\title{
Synthesis and Characterization of Polyimide-Silica Hybrids: Effect of Matrix Polarity on the Mechanical and Thermal Properties
}

\author{
H. U. REHMAN, ${ }^{1}$ H. SCHMIDT, ${ }^{1}$ AND Z. AHMAD ${ }^{2}$ \\ ${ }^{1}$ Institut fur Neue Materialien, Im Stadtwald, Saarbrucken, Germany \\ ${ }^{2}$ Department of Chemistry, Kuwait University, Faculty of Science, \\ Safat, State of Kuwait
}

\begin{abstract}
Polyimide silica hybrid materials have been prepared through the sol gel process by mixing various proportions of tetraethoxysilane (TEOS) with polyamic acids (PAAs). Two types of PPAs were employed. The first was obtained by reacting an equimolar mixture of oxydianiline (ODA) and pyromellitic dianhydride (PMDA) in dimethylacta mide (DMAc) as solvent. The second was prepared using a mixture of ODA and 2,2 Bis(3 amino 4 hydroxyphenyl)hexafluoropropane (6F OHDA) in molar ratio 9:1, respectively and reacting with a stoichiometric amount of PMDA in DMAc. Polyamic acids were converted to polyimides and a sol gel reaction proceeded simul taneously by heating the hybrid films to $300^{\circ} \mathrm{C}$. The hydroxyl groups from $6 \mathrm{~F} O H D A$ allows the secondary bonding between the polyimide and growing silica phase and thus retard the gross phase separation. Only the 10 mol\% addition of $6 F$ OHDA in the polyimide chain resulted in a drastically different microstructure for the resulting hybrids. SEM, stress strain analysis, temperature variation of storage and loss modulus, and thermal stability were used to characterize the hybrid materials. Properties of both types of hybrids have been compared and related to the two different types of structures of polyimides used in the preparation of the hybrids.
\end{abstract}

Keywords poly(flouro hydroxy imide), silica, hybrids, sol gel process

\section{Introduction}

An aromatic type of polyimides (PIs) $(1,2)$ have been extensively studied in relation to the manufacture of microelectronic devices because of their good chemical, physical and thermal properties. However, relatively higher coefficient of thermal expansion (CTE) of PIs cause serious reliability problems such as, bending, curling, cracking and de-lamination, when used in multi-layer structures. Inorganic materials, on the other hand, exhibit excellent thermal stability and high modulus, but high brittleness and bad film-forming characteristics. Thus, the formation of hybrid composites of polyimide with inorganic materials has been suggested to meet the demand of balanced properties for both organic and inorganic materials. Since thin films are required in microelectronics

Address correspondence to Z. Ahmad, Department of Chemistry, Kuwait University, Faculty of Science, P.O. Box 5969, Safat 13060, State of Kuwait. Tel.: + 965 4985326; Fax: +965 4816482; E mail: zahmad@kuc01.kuniv.edu.kw 
and photonic applications, a different process must be applied instead of conventional composite preparation technique used for carbon and glass fiber reinforced plastics. In addition, the thermodynamic immiscibility between organic and inorganic materials, may lead to phase separation in the resultant hybrid films. The control of metal oxide particle size is therefore important for thin films with good mechanical properties. It should be far below the micrometer scale in order to achieve high transparency of the films needed for many applications $(3,4)$. Thus, it has been a challenge to finely disperse the inorganic phase in polymer matrices. However, even though particles of small size can be achieved they are commonly aggregated up to sub-micrometer or micrometer scale during conventional composite formation. One reasonably good approach is the sol-gel process $(5,6)$, which can produce fine particles uniformly dispersed in the matrix through in-situ polymerization of monomeric precursors. Increased interfacial interaction or bonding between the phases further helps to achieve uniform distribution with reduced inorganic particle size in the matrix. Ahmad and Mark have reviewed different methods used in the last decade for effectively introducing inorganic phases in PIs (7) and other polymers (8).

McGrath and coworker (9) first reported the synthesis of functionalized PI oligomers capable of bonding themselves into sol-gel networks. Since only oligomers were used in this case, the mechanical properties of the resulting hybrid material were not studied. Nandi et al. $(9,10)$ in their preparation of the PI-silica hybrids materials used the metal alkoxide together with pyromellitic anhydride (PMDA) and oxydianiline (ODA), the monomers required to prepare the PI precursor polyamic acid (PAA). The resulting polymeric mixtures were cast into films and cured at $300^{\circ} \mathrm{C}$. It was believed that the hydrolysis of metal alkoxides takes place with the water released in the imidization process. This strategy, yielded transparent films with particle size less than $1.5 \mu \mathrm{m}$ up to $42 \%$ silica content.

Morikawa et al. (11) introduced functional groups in the polymer backbone using alkoxysilated diamine in place of ODA, which provided bonding sites on the chains. Properties of the hybrid films prepared using different types and concentrations of the pendant alkoxy side chain were reported. Films transparency increased with increasing ethoxysilyl group content in the imide matrix. SEM results showed that the silica particle size was 0.5 $1.0 \mu \mathrm{m}$, i.e., smaller than found ( $37 \mu \mathrm{m}$ ) in their previous studies (12) where no bonding sites on the polymer chain were available. In contrast to previous studies (12), the tensile strength of the hybrid materials showed no decrease with an increase in the silica content.

Wang and Ahmad (13, 14), Schrotter et al. (15), Chen et al. (16), and Chang et al. (17) have separately prepared PI-silica hybrids using tetraalkoxysilane with different aminoalkoxysilanes; aminophenyl-trimethoxysilane (APTMOS), aminopropyl-trimethoxysilane (APrTMOS), diaminophenyltetramethyl-disiloxane, aminopropylmethyl-diethoxysilane, diaminopropyltetramethyl-disiloxane, and phen(aminoethylaminomethyl)phenyl ethyl-trimethoxysilane. The amino groups present on the silane were supposed to interact with PAA, and alkoxy groups during the sol-gel process become the part of the silica network. The presence of a chemical bond between the PI and silica had pronounced effects on the properties of the films, especially on their optical and mechanical properties. The elongation moduli and ultimate strength increased and the elongation at break decreased with increase in silica content.

The compatibilization of PI-silica hybrids has also been reported by Mascia and Kioul $(18,19)$ and Menoyo et al. (20) who used a glycidyl and isocyanate type of trialkoxysilanes to couple the PAA to silicate network prior to the condensation reactions for the formation of ceramers. The morphology of the hybrid films was found to be strongly 
dependent on the molecular weight of the PAA, the reaction time for the solution mixture and the type and the proportion of coupling agent used. The use of an extensive amount of trialkoxysilane coupling agent (21) caused retardation in gelation reactions.

Ree et al. prepared PI-silica nano-composites films for use in fabrication of microelectronic devices by the solution blending of PAA and silica aerogels (22). Optical and dielectric properties were found to improve. S. Raun et al. prepared tough PI hybrids (23) by hot-pressing a mixture of PI and highly porous silica powder. The effect of loading, cure and post cure temperature on fracture toughness were investigated. The addition of silica was found to improve fracture toughness of the material. J.C. Huang et al. (24) prepared PI materials with a low value of CTE, while still retaining high strength and toughness. The silica was incorporated through a sol-gel process in homoand co-polyimides with highly rigid chain structures. G.H. Hsiue et al. (25) carried out the preparation of PI-silica nano-composites using a non-aqueous sol-gel process by polycondensation of phenyltriethoxysilane (PTEOS) in PAA solution. ${ }^{29} \mathrm{Si}$ NMR spectra of the silicate structure in the nano-composites showed that the proportion of the nonhydroxy-substituted silica increase with increase in the silicon content. This implies that increasing the silicon content of the polyimide-silica hybrid can favor the formation of silica glass structure, thus providing a more complete silica structure. The glass transition temperatures $\left(\mathrm{T}_{\mathrm{g}}\right)$ of the polyimide-silica hybrids increased with an increase in the silica contents.

M.H. Tsai recently reported (26) low dielectric polyimide-silica hybrids prepared from polyimide precursor containing PTEOS at two chain ends and monoaryl-trialkoxysilane using a self-catalyzed sol-gel process. The dielectric constant and water absorption in the hybrid materials was found to reduce with the PTEOS content. Dynamic mechanical properties of these hybrids have recently been studied by the same author (27). It was found that reducing the imide blocks of the linear chain in the three dimensional silica network structures enhances the storage and the tensile modulus and $T_{g}$, but reduces the relaxation damping peak, density and strain values at break point. A series of hybrid PI-silica composites has been prepared from a functionalized fluorinated PI and tetra-methoxysilane (TMOS), methyl-triethoxysilane (MTMOS), and phenyl-trimethoxysilane (PTMOS) via the sol-gel process by C.J. Cornelius et al. (28). PIs were solution imidized employing the 4,4'-hexa-fluroisopropylidene-diphthalic anhydride and various amounts of the 4,4'-hexa-fluroisopropylidene dianiline and 3,5-diaminobenzoic acid. The degree of crosslinking between the silica structures and the imide matrix, as well as the morphology of the hybrid materials, were found highly dependent on the type and content of the alkoxide employed. The high functionality and reactivity of the TMOS gave rise to highly crosslinked, homogenous hybrid films, while the MTMOS and PTMOS based hybrid films were phase separated and the silica structures largely remained uncondensed. Although the thermal stability of the hybrid films changed a little, the incorporation of the silica structures in the PI matrix increased the rigidity and the mechanical strength of the resulting hybrid materials, particularly at higher temperatures.

The silica network in the PI matrix has recently been modified by Qui et al. (29) using different proportions of tetrabutyl titanate (TBT) along with TEOS during the sol-gel process. The inorganic particles show a much more homogenous distribution and a very fine inter-connected domains with reduced size as compared to binary hybrids with similar concentration of metal oxide. The interaction between the particles and the matrix increased significantly particularly when TBT was used in equal molar ratio to TEOS.

This paper describes the synthesis and characterization of PI-silica hybrids where the PI matrix has been modified to include flouro- and hydroxyl-groups on the chain. The 
hydroxyl pendant groups on the chain are expected to increase the interfacial interaction between the matrix and the silica network where as presence of fluorine can reduce refractive index of the hybrid films and add resistance to wear and abrasion. Two types of PAAs were prepared, one, without pendant hydroxyl groups prepared by the reaction of 4,4-oxydianiline (ODA) with stoichiometric amount of pyromellitic dianhydride (PMDA) in DMAc as solvent, and second, having pendant hydroxyl groups was synthesized by the copolymerization of a mixture of ODA and appropriate amounts of 2,2-bis(3-amino-4hydroxyphenyl)hexafluoropropane (6F-OHDA) with PMDA in DMAc. Hybrids sols having different amounts of silica in these matrices were prepared through the sol-gel process and then cured to form PI. The morphology, thermal and mechanical properties of both types of hybrid materials have been compared and related to the two different types of chain structures used in the matrix.

\section{Experimental}

\section{Chemicals}

The monomers employed for the preparation of polymer matrices, 4,4-oxydianiline (ODA), pyromellitic dianhydride (PMDA) and 2,2-bis(3-amino-4-hydroxyphenyl) hexafluoropropane (6F-OHDA) were of AR grade. The first two monomers were obtained from Fluka and 6F-OHDA from Fluorchem, Inc. These were used without further purification. Anhydrous dimethylacetamide (DMAc) with water content less than $0.005 \%$ was obtained from Aldrich. Tetraethoxysilane (TEOS) was obtained from Gelest Inc. and used as received.

\section{Synthesis of PAAs}

The PAA without pendant hydroxyl groups was prepared by the reaction of ODA with stoichiometric amount of PMDA in DMAc. In a typical synthesis, $250 \mathrm{ml}$ flask with nitrogen gas inlet and outlet and magnetic stir bar was charged with $25 \mathrm{mmol}(5.006 \mathrm{~g})$ of ODA and $140 \mathrm{~g}$ DMAc. This amine solution was stirred for $15 \mathrm{~min}$ under nitrogen. A stoichiometric amount of PMDA, $25 \mathrm{mmol}(5.453 \mathrm{~g}$ ), was added at once to the vigorously stirred amine solution, which resulted in a highly viscous PAA solution. The solution was

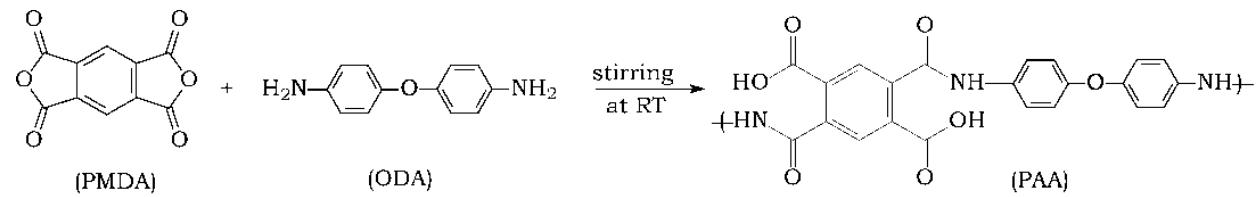<smiles>Cn1c(=O)c2cc3c(=O)n(-c4ccc(Oc5ccc(N)cc5)cc4)c(=O)c3cc2c1=O</smiles>

Scheme 1. Chemical synthesis of polyimide (PI) matrix. 
stirred for an additional $20 \mathrm{~h}$ for complete reaction. The chemical reaction leading to the formation of PAA is given in Scheme 1.

For the synthesis of PAA having pendant hydroxyl groups in the main chain, an almost similar procedure was adopted, except that in this case a mixture of ODA and 6F-OHDA in a molar ratio 90:10 (total amount equivalent to $25 \mathrm{mmol}$ ), was taken in $120 \mathrm{~g}$ of DMAc as solvents. The resulting mixture was stirred at $20^{\circ} \mathrm{C}$ for $15 \mathrm{~min}$ under $\mathrm{N}_{2}$ to ensure complete mixing $25 \mathrm{mmol}$ of PMDA were added at once to the stirring mixture. After about $1 \mathrm{~h}$ of stirring, viscosity of PAA was found to increase sharply. To facilitate stirring, more $20 \mathrm{~g}$ DMAc was added and the solution was stirred for a further $20 \mathrm{~h}$ to complete the reaction. The chemical structure of the resulting PAA with randomly distributed hydroxyl groups is given in Scheme 2.

\section{Preparation of the Hybrid Films}

Various proportions of TEOS were mixed in the PAA solutions to yield hybrids with different silica contents in the matrix. In situ hydrolysis and condensation were carried out by adding the required stoichiometric amount of water (as $20 \% \mathrm{w} / \mathrm{w}$ of $0.1 \mathrm{M} \mathrm{HCl}$ in DMAc). The resulting mixtures were stirred for $18 \mathrm{~h}$. Thin films were cast in Teflon Petri dishes. Solvent elution was carried out at $70^{\circ} \mathrm{C}$ for $12 \mathrm{~h}$ and then at $80^{\circ} \mathrm{C}$ for an additional $2 \mathrm{~h}$ under vacuum. Imidization was carried out by successive heating at $100^{\circ} \mathrm{C}, 200^{\circ} \mathrm{C}$ and $300^{\circ} \mathrm{C}$ each for $1 \mathrm{~h}$ under nitrogen. Hybrids prepared using PI and polyhydroxyimide (PHI) matrices are named as PIHs and PHIHs, respectively along with the digits giving silica vol\% used in the matrix. The flow sheet diagram illustrating the preparation of these hybrids is given in the Figure 1.

\section{Characterization}

FTIR analysis to follow the imidization process and the silica network formation in the hybrids was carried out in the $4004000 \mathrm{~cm}^{1}$ range using a Bruker FTIR
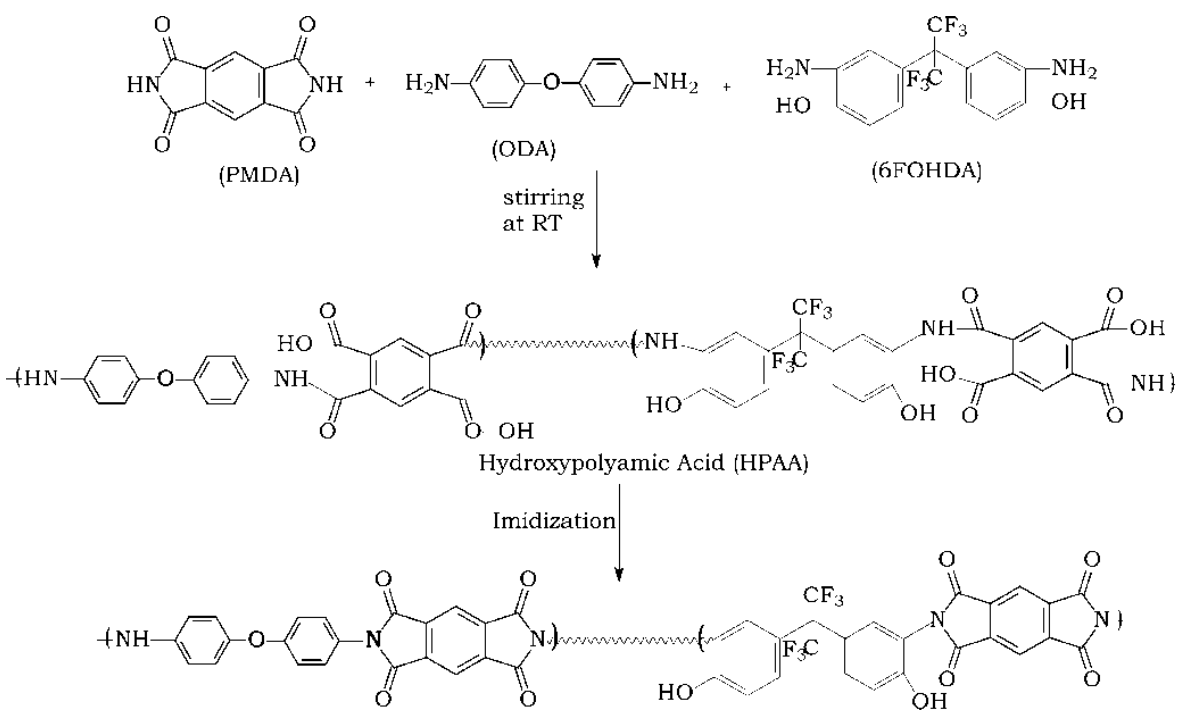

Scheme 2. Chemical synthesis of hydroxy polyimide (HPI) matrix. 


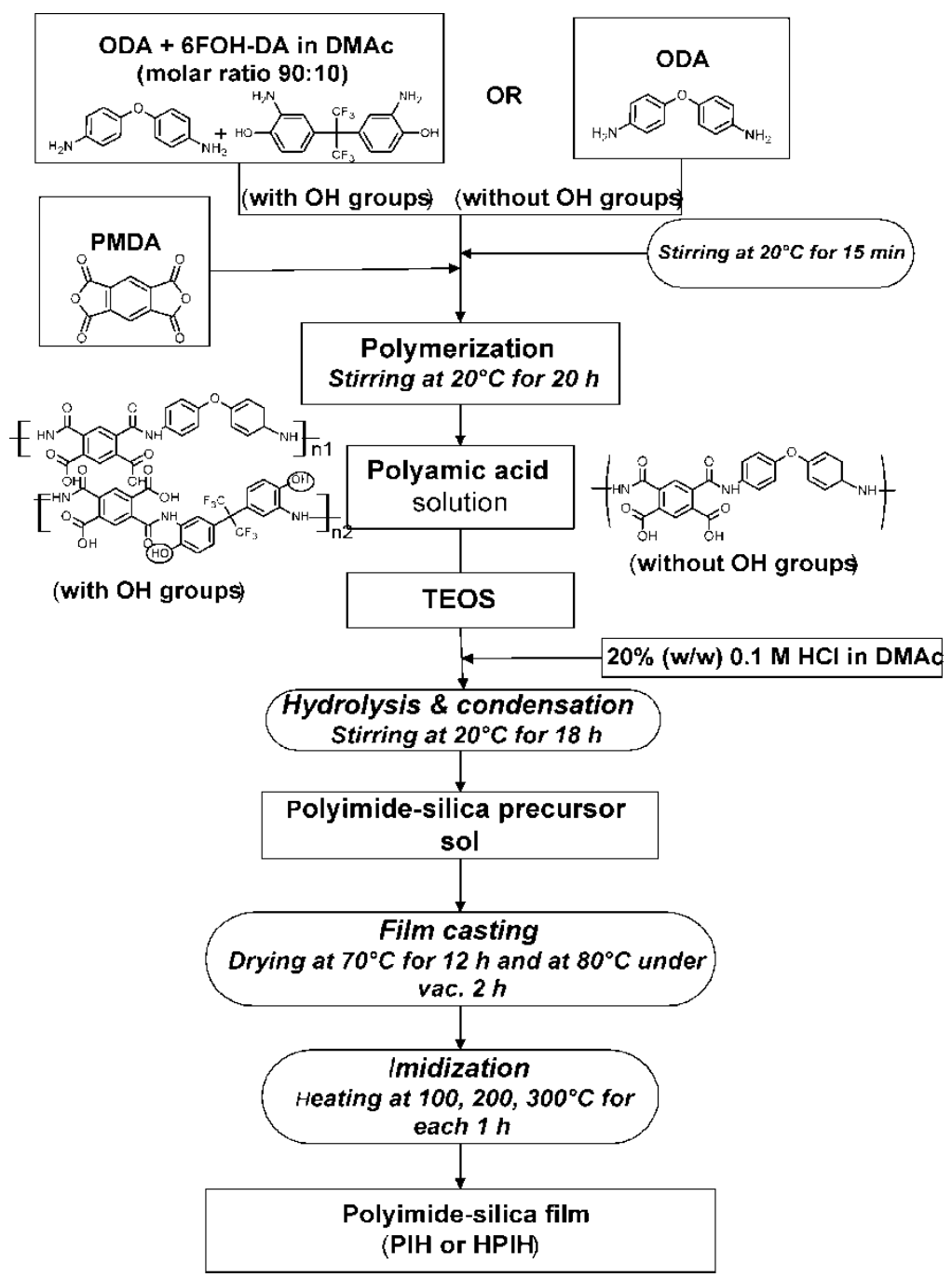

Figure 1. Flow chart for the synthesis of PIHs and HPIHs.

spectrophotometer. Stress-strain measurements were made on hybrid films under a DIN procedure 53455. The test was performed on a Zwick Testing Machine, Model 1446. A crosshead speed of $5 \mathrm{~mm} / \mathrm{min}$ was used to measure the tensile properties. At least five samples were tested for each composition and the average values are reported. Dynamic mechanical thermal analysis (DMTA) was conducted on a MKIII Dynamic Viscoelastometer (Rheometric Scientific Inc.) at a fixed frequency of $10 \mathrm{MHz}$. All the measurements were carried out under the tensile mode from 100 to $500^{\circ} \mathrm{C}$ at a heating rate of $2^{\circ} \mathrm{C} / \mathrm{min}$. Thermogravimetric analysis (TGA) was performed on a Bähr Garätebsau STA-501 by taking a $4050 \mathrm{mg}$ sample in $\mathrm{Al}_{2} \mathrm{O}_{3}$ crucibles, which was heated from $100^{\circ} \mathrm{C}$ to $1000^{\circ} \mathrm{C}$ at a ramp rate of $10^{\circ} \mathrm{C} / \mathrm{min}$ under synthetic air with a gas flow rate of $50 \mathrm{cc} / \mathrm{min}$. Scanning electron microscopy (SEM) measurements were conducted with a JEOL, JSM $6400 \mathrm{~F}$ at $10 \mathrm{kV}$. 


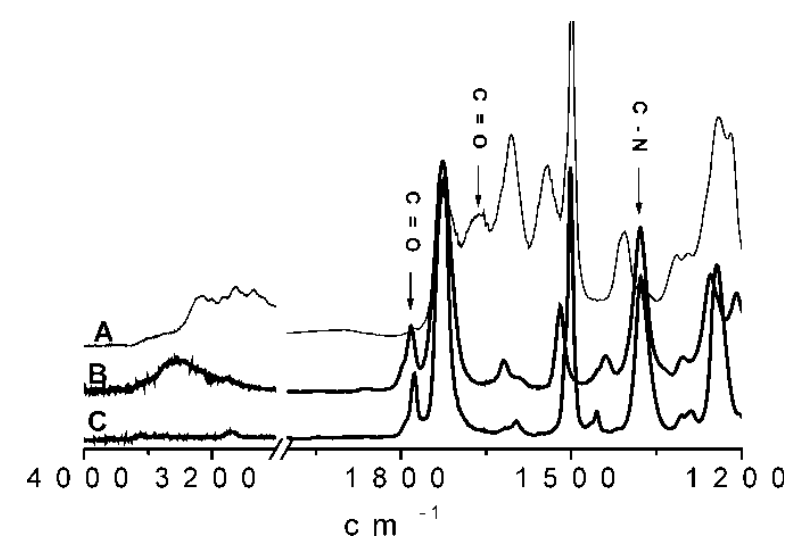

Figure 2. FTIR spectra of PAA dried at $100^{\circ} \mathrm{C}$ (A), PHI (B) and PI (C), imides films heat treated at $100^{\circ} \mathrm{C}, 200^{\circ} \mathrm{C}$, and $300^{\circ} \mathrm{C}$ for $1 \mathrm{~h}$ each under nitrogen atmosphere.

\section{Results and Discussion}

\section{FTIR Analysis}

Figure 2 shows the relevant sections of the FTIR spectra of PAA, PI and PHI. The most important regions are $17701782 \mathrm{~cm}^{1}$ and $13771382 \mathrm{~cm}^{1}$ resulting from $\mathrm{C}=\mathrm{O}$ and C N vibrations, respectively. In the case of PAA, three absorption peaks around 2800 3300,1668 , and $1545 \mathrm{~cm}^{1}$ appears, corresponding to $\mathrm{N} \mathrm{H}, \mathrm{C}=\mathrm{O}$ and $\mathrm{C} \mathrm{NH}$ stretching vibrations, respectively. The broad band around $1660 \mathrm{~cm}^{1}$, called amide I, and around $1540 \mathrm{~cm}^{1}$, known as amide II, are characteristic modes (30) of PAA. These bands disappeared entirely after the thermal imidization, and new strong absorption bands at 1777 1782,17221730 , and $13771380 \mathrm{~cm}^{1}$ due to the asymmetric stretching of $\mathrm{C}=\mathrm{O}$, symmetric stretching of $\mathrm{C}=\mathrm{O}$ and symmetric stretching of $\mathrm{C} N$, respectively, can be assigned (31) to the imide ring. The appearance of these characteristic absorption bands confirms the curing of PAA to corresponding imide chain. Figure 2 also shows the FTIR spectra in the range of $28004000 \mathrm{~cm}^{1}$ for PAA, PI and PHI. The band corresponding to $\mathrm{NH}$ and $\mathrm{OH}$ stretching vibrations which appears in the $32003600 \mathrm{~cm}{ }^{1}$ range can clearly be observed in PAA. When it was cured, all the absorption peaks due to $\mathrm{N} \mathrm{H}$ and $\mathrm{OH}$ stretching were eliminated for PI. However, a strong and broad absorption band centered around $3500 \mathrm{~cm}^{1}$ in the case of cured PHI (obtained from $100 \mathrm{~mol} \%$ of $6 \mathrm{~F}-\mathrm{OHDA}$ and PMDA) confirms the presence of free hydroxyl groups after the curing process.

To study the structure of the growing silica network in PIH and PHIH, the FTIR spectra recorded with $14.4 \mathrm{vol} \%$ of silica in these matrices along with that of pure PI are shown in Figure 3. Since these hybrids were insoluble in organic solvents, their spectra were recorded on $\mathrm{KBr}$ pellets using crushed hybrid powders. The absorption bands at $1777 \mathrm{~cm}{ }^{1}$, $1377 \mathrm{~cm}^{1}$ and $725 \mathrm{~cm}^{1}$ corresponding to $\mathrm{C}=\mathrm{O}$ asymmetric stretching, $\mathrm{C} \quad \mathrm{N}$ stretching and $\mathrm{C}=\mathrm{O}$ bending vibration, respectively confirm the imide formation showing that growing silica phase virtually has no effect upon the imidization process. Since some bands of polyimide matrix are located in close proximity to the silicon oxide peaks, it poses difficulty in analyzing the siloxane peaks. In the absorption domain ranging from $850 \mathrm{~cm}^{1}$ and $1250 \mathrm{~cm}^{1}$, the shoulder around $1085 \mathrm{~cm}^{1}$, along with broadband around $960 \mathrm{~cm}{ }^{1}$, confirms the formation of a silica network. The hybrids prepared from the PI appeared the strongest, while that from PHI exhibited the smallest absorption in the 


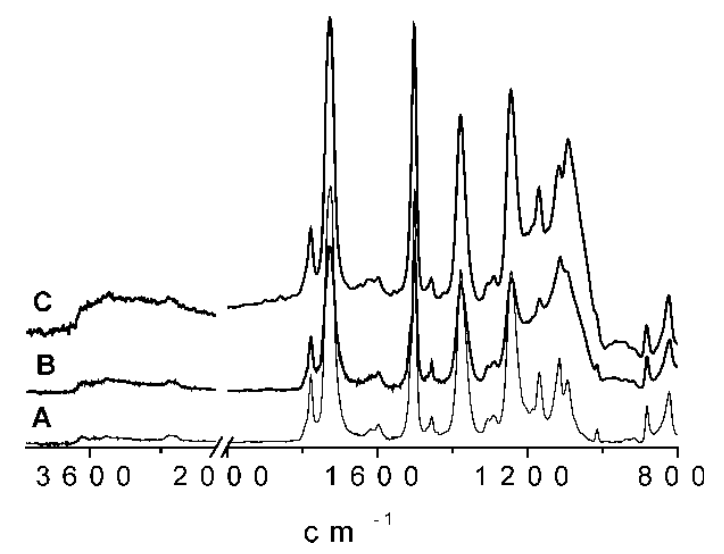

Figure 3. FTIR spectra of PI (A), PHIH 14.4 (B) and PIH 14.4 (C).

$3600 \mathrm{~cm}^{1}$ region. The higher frequency absorption (around $3650 \mathrm{~cm}^{1}$ ) present in all hybrids can be attributed to the free $\mathrm{Si}-\mathrm{OH}$ groups. Lower intensity of $\mathrm{Si}-\mathrm{OH}$ absorption in the case of PHIH-14.4 suggests that the hydroxyl groups on the polymer chains were involved in the hydrolysis and condensation process with TEOS, resulting in the binding between the growing silica network and PHI chain.

\section{SEM Studies}

The scanning electron micrographs in Figure 4 (a d) show the effect of matrix modification and silica loading on the morphology of the resulting hybrids. As can be seen from Figure $4 \mathrm{a}$, in the case of PIH, there is a gross phase separation of silica particles with the diameter of the particles ranging from 1 to $1.5 \mu \mathrm{m}$. Such particle distribution is evidence of phase separation by spinodal decomposition. As the silica concentration is increased from $5.8 \mathrm{vol} \%$ to $14.4 \mathrm{vol} \%$, the particle diameter increased from 1 to $4 \mu \mathrm{m}$ in the case of PIHs (Figure 4c), but the increase due to higher silica loading is much less in the case of PHIHs (Figures 4 (b and d)). The silica particles are more bonded with the matrix in case of PHIHs. A good adhesion, coupled with small particle size, can be attributed to the enhanced polarity of the PHI matrix brought about by the hydroxyl groups present along the polymer chain. These hydroxyl groups on the chain may act as bonding sites for the silicate phase thus retarding their gross phase separation from the matrix.

\section{Mechanical Properties}

Figure 5 shows typical stress-strain curves for PI, PIH-11.5 and PHIH-11.5. The stress-strain behavior varies considerably for both hybrids. Relative low strength and higher strain for PIH is typical inert filler behavior, while higher strength and relatively small strain for PHIH represents a bonded system. The tensile modulus of PIHs and PHIHs as a function of silica concentration is shown in Figure 6. The theoretical curves based upon the theories given by Kerner (32) and Counto (33) are shown for comparison. Calculations used in the Counto theory are based on the assumption that a perfect adhesion exists between the various phases of a composite. Kerner's theory on the other hand does not take into account that any such interactions between the phases and modulus increase 


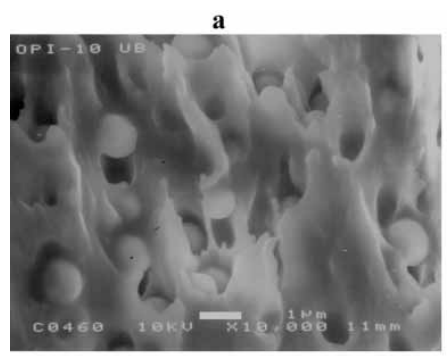

$1 \mu \mathrm{m}$

c

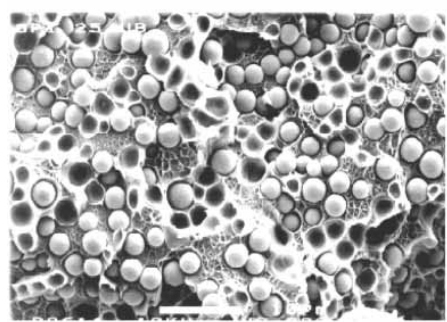

$10 \mu \mathrm{m}$

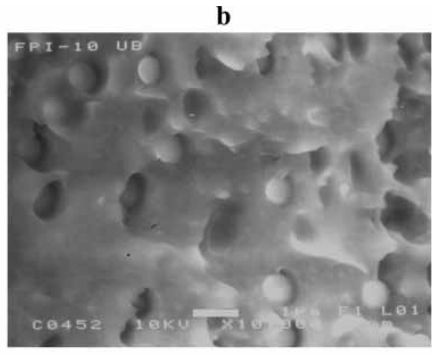

$1 \mu \mathrm{m}$

d

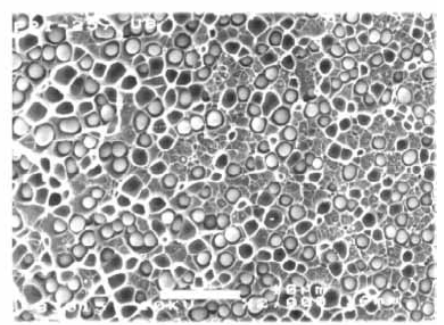

$10 \mu \mathrm{m}$

Figure 4. SEM micrographs of PIHs and PHIHs showing the effect of matrix polarity on the morphology: a) PIH 5.8, b) PHIH 5.8, c) PIH 14.4 and, d) PHIH 14.4.

solely arises from the increased volume fraction of the filler. The modulus was found to increase with increased silica fraction in both cases. PHIHs had a higher modulus than the PIHs. Since PHIHs consist of smaller silica particles (in the range of $0.11 .5 \mu \mathrm{m}$ ) as compared to that of PIHs (in the range of $24 \mu \mathrm{m}$ ), as observed from the SEM study, these particles have a high surface to volume ratio. More surface area available to bond/absorb the polymer chains for a given silica content, makes the polymer chains stiff which explains why the PHIHs had higher Young's modulus than that of the PIHs

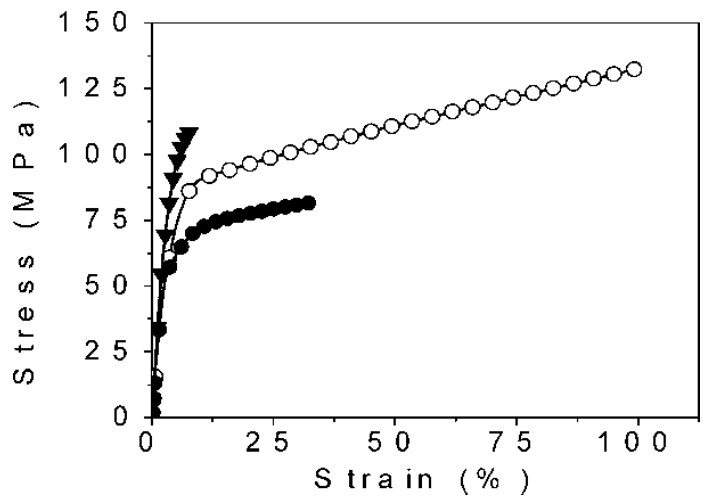

Figure 5. Stress strain behavior: PI (०), PIH $11.8(\bullet)$, and PHIH $11.8(\boldsymbol{\nabla})$. 


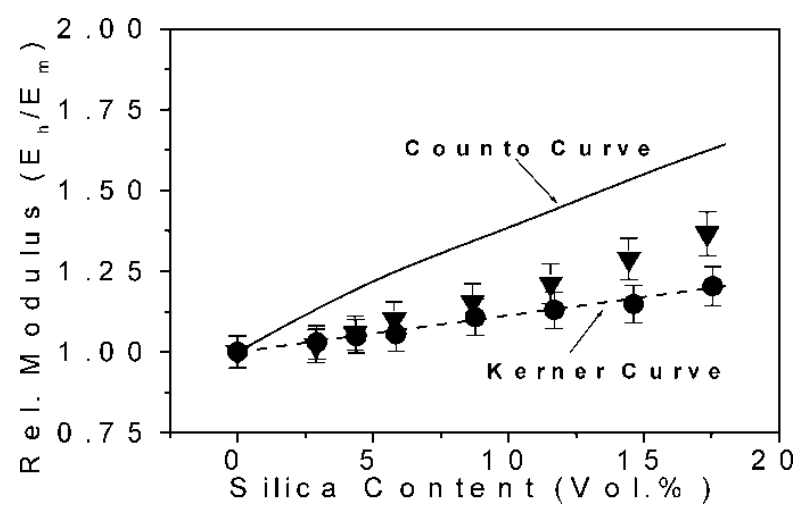

Figure 6. Relative modulus for PIHs ( $\bullet$ ) and PHIHs ( $\mathbf{\nabla})$ as a function of silica content in compari son with theoretically calculated modulus values from Kerner (32) and Counto (33) theories.

for the same silica loading. The variation of tensile strength with the silica content for both types of hybrids is shown in Figure 7. For PIHs, the strength decreased monotonously with increasing amount silica. The stress values lie very close to the Nielsen's theoretical curve (34), up to ca. 11 vol\% of silica, and above this, the concentration is dropped below the curve. In comparison to the PIHs, the PHIHs showed higher tensile strength than that of a pure matrix. The strength increases on increasing the silica content to ca. $10 \mathrm{vol} \%$, but then it decreases, reaching a plateau at 17 vol\% silica loading. However, these values lie well above the theoretical values for the silica loading studied. The strength of a particulate system depends upon three factors i.e., elastic modulus, fracture energy and the crack size, and are influenced by the particulate phase. As a general rule, the larger particles enhance the fracture energy, which in turn enhances the strength of the composite materials. However, at the same time, the larger particles are more effective precursors for crack initiation. Higher modulus also results in higher strength. Crack size on the other hand acts as a void and decreases the strength. Lower strength has been reported if there is weak bonding between the organic polymer phase and the inorganic ceramic phase. In this case, the silica acts as non-reactive, non-reinforcing filler.

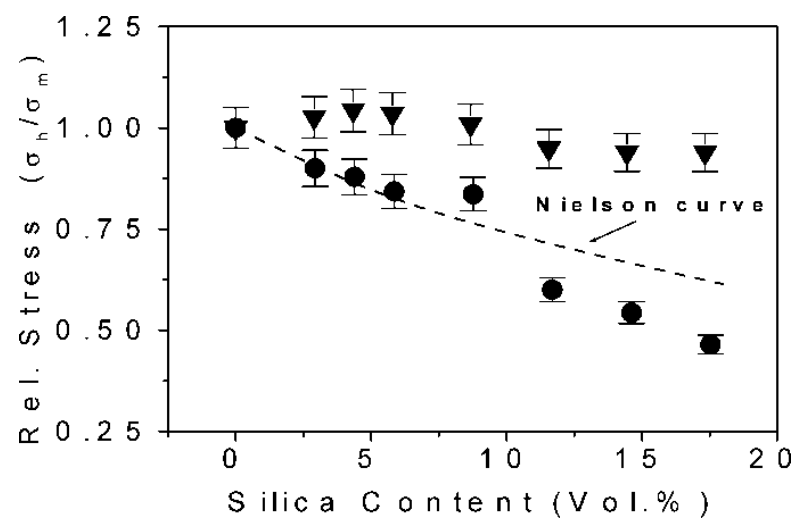

Figure 7. Tensile strength of PIHs $(\bullet)$ and PHIHs $(\boldsymbol{\nabla})$ as a function of silica content. For compari son, theoretical curves based upon the Nielsen's theory (34) are shown. 
It is well documented in the literature $(12,35)$ that strength of the hybrid materials is reduced when there are no bonding sites between the organic and inorganic phases. Since these hybrids have a sufficiently high molecular weight PI, therefore, phase separation between the polymer and polysilicate occurred easily. As the external stresses on a plastic composite are transferred from polymer matrix to the filler, the ultimate properties of the hybrid materials are dependent on the extent of bonding between the two phases and the surface area of the filler, and the arrangements between the filler particles. The PHIHs system therefore, shows better tensile strength as compared to PIHs for the similar silica loading.

\section{Dynamical Mechanical Thermal Analysis}

The variation of loss modulus ( $\tan \delta$ ) with temperature for PI, HPI, PIH-5.8 and PHIH-5.8 is presented in Figure 8. Comparison of the peak height of the PI matrix with that of PHI matrix shows that PHI matrix has higher value of $\tan \delta$ than that of PI (Table 1). This can be attributed to the enhanced amorphous character induced by the addition of $10-\mathrm{mol} \%$ of 6F-OHDA. Since 6F-OHDA contains bulky hexafluoroisopropylidene group along with two hydroxyl pendent groups, which may hinder the close packing of the polyimide chains, as a result the free volume of the PHI film is subsequently increased. The magnitude of the $\tan \delta$ curves decreases with further increasing the amount of silica (Table 1). The $\mathrm{T}_{\mathrm{g}}$ associated with $\alpha$-relaxation measured from the maxima of the curve for PIHs is not altered, a typical behavior of the inert fillers, since the properties of the polymer chain has no interaction with the silica network. On the other hand, for PHIHs an increase of about $8^{\circ} \mathrm{C}$ in $\mathrm{Tg}$ was observed with increasing silica content. This suggests that polymer molecules are adsorbed/reacted on the silica surface and as a result their mobility is restricted. This was further evident from the damping in the tan $\delta$ values as compared to pure matrix. This large reduction in the $\tan \delta$ curves and increase in $\mathrm{Tg}$ for PHI hybrids can be attributed to the enhanced miscibility/chemical bonding between the organic and inorganic phases as a result of the hydroxyl groups present along the polymer chains.

The variation of storage modulus vs. temperature for PI, HPI, PIH-5.8 and PHIH-5.8 systems is shown in Figure 9. As expected, the storage modulus drops to about an order of

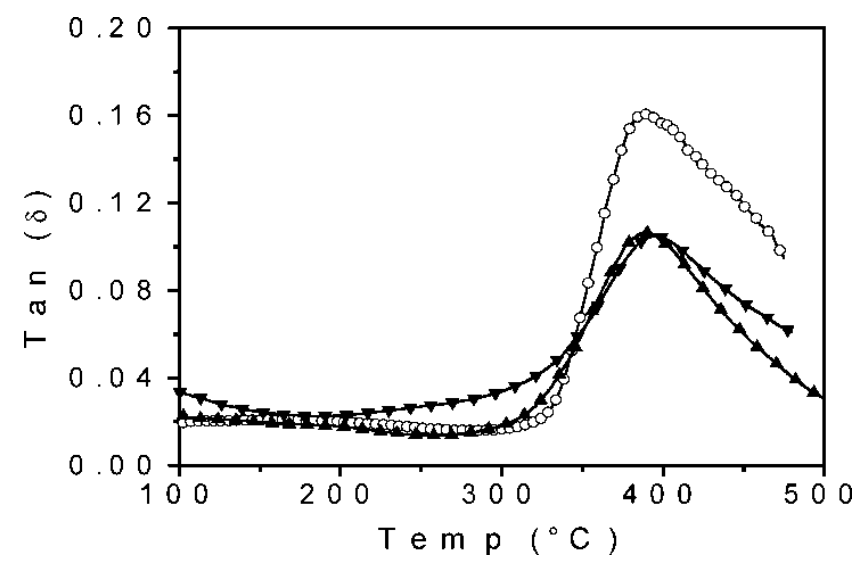

Figure 8. Variation of the loss tangent $(\tan \delta$ ) with temperature for PI (o), PIH $5.8(\boldsymbol{\Delta})$ and PHIH $5.8(\boldsymbol{\nabla})$. 
Table 1

Thermoelastic properties of the polyimide-silica hybrids

\begin{tabular}{lccc}
\hline $\begin{array}{l}\text { Hybrid } \\
\text { system }\end{array}$ & $\begin{array}{c}\mathrm{E}^{\prime}(\mathrm{GPa}) \text { at } \\
100^{\circ} \mathrm{C}\end{array}$ & $\begin{array}{c}\mathrm{E}^{\prime}(\mathrm{MPa}) \text { at } \\
450^{\circ} \mathrm{C}\end{array}$ & $\begin{array}{c}\text { Tan } \delta \text { peak } \\
\text { height }\end{array}$ \\
\hline PI & 2.63 & 506 & 0.128 \\
PI-5.8 & 2.39 & 527 & 0.110 \\
PI-8.8 & 2.58 & 622 & 0.105 \\
PI-11.8 & 2.81 & 658 & 0.097 \\
PI-14.4 & 3.38 & 875 & 0.090 \\
HPI & 2.57 & 606 & 0.168 \\
HPI-5.8 & 3.55 & 946 & 0.115 \\
HPI-11.8 & 3.97 & 992 & 0.105 \\
HPI-14.4 & 4.16 & 1315 & 0.100 \\
\hline
\end{tabular}

magnitude in the rubbery region in the case of pure PI. The PIHs samples with silica contents greater than $5.8 \mathrm{vol} \%$, all have higher $\mathrm{E}^{\prime}$ values in the rubbery region compared to the pure PI (Table 1). In the case of PHIHs, the storage modulus linearly increases with an increasing amount of silica at $100^{\circ} \mathrm{C}$, as well as in the rubbery region showing an improved adhesion between the two phases. The modulus decreases linearly with temperature up to about $340^{\circ} \mathrm{C}$ and at $\mathrm{T}_{\mathrm{g}}$, a rapid decrease in $\mathrm{E}^{\prime}$ is witnessed. The rate of decrease of $\mathrm{E}^{\prime}$, however, was considerably less with large silica contents. Further PHIHs showed a higher value of E' with an increase in silica loading both at $100^{\circ} \mathrm{C}$ and above the $\mathrm{T}_{\mathrm{g}}$. Figure 10 shows the variation of storage modulus $\mathrm{E}^{\prime}$ vs. silica content at $450^{\circ} \mathrm{C}$ for both types of hybrid materials. There is a significant influence of the silica content on the storage modulus at $450^{\circ} \mathrm{C}$ for PHIHS as compared to that of PHI hybrids. The higher values of moduli in case of PHIHs is most likely due to the syneresis process (36) attributed to the co-condensation of the hydroxyl groups of the matrix with the $\mathrm{OH}$ groups on the silica particles. Through this reaction, the two phases bonded to each other contribute to enhance the network density of the materials which

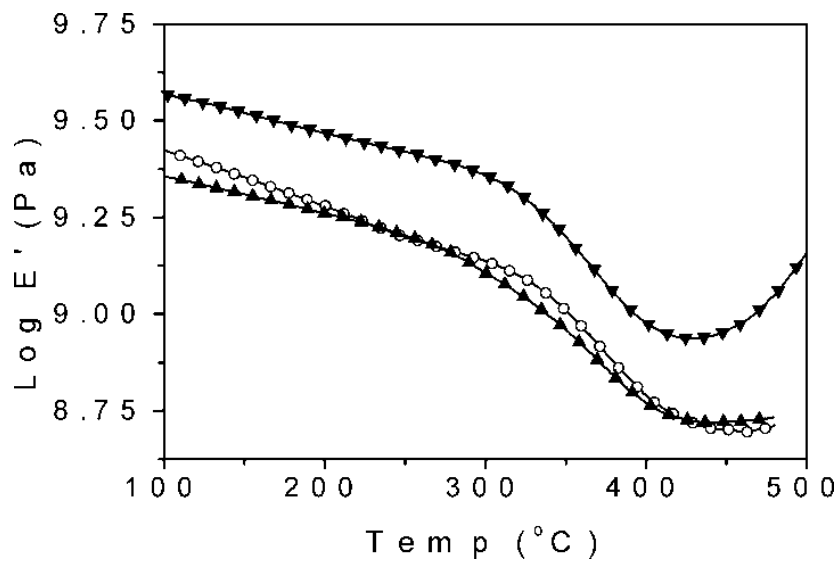

Figure 9. Variation of storage modulus with temperature for PI (०), PIH $5.8(\boldsymbol{\Delta})$ and PHIH $5.8(\boldsymbol{\nabla})$. 


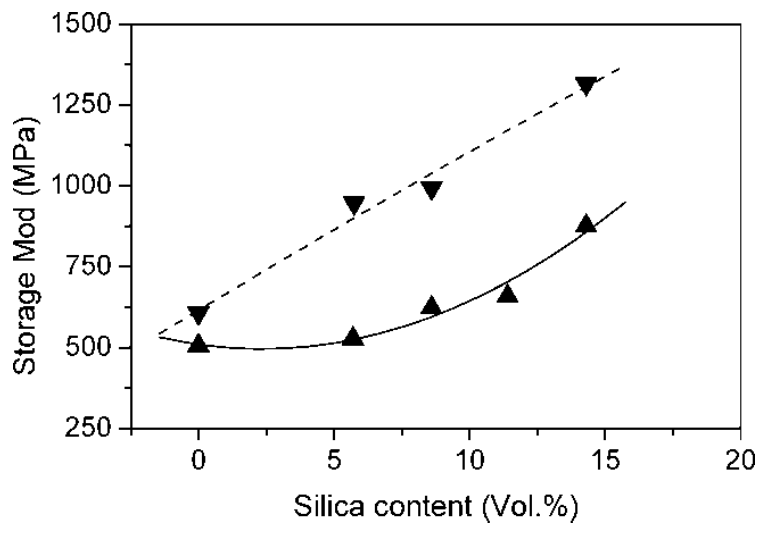

Figure 10. Storage modulus of PIHs ( $\boldsymbol{\Delta}$ ) hybrids and PHIHs ( $\boldsymbol{\nabla}$ ) vs. silica contents in the rubbery regime; temperature $450^{\circ} \mathrm{C}$.

in turn is responsible for higher $\mathrm{E}^{\prime}$ values. Comparatively lower $\mathrm{E}^{\prime}$ values of PIHs in the rubbery region clearly show that PIHs are highly phase separated, as already confirmed by SEM analysis.

\section{Thermal Stability}

Figure 11 shows the TGA curves for pure PI, PI-5.8 and PHI-5.8 hybrids, and Table 2 gives the temperatures for the required weight loss values. A slight decrease in the weight below $500^{\circ} \mathrm{C}$ for the hybrids could be due to the loss of by-products $\left(\mathrm{H}_{2} \mathrm{O}\right.$, EtOH) from the condensation reaction of the silica network. Taking 5 wt.\% loss as thermal decomposition temperature, it is found that $\mathrm{PHI}$ decomposes at around $510^{\circ} \mathrm{C}$ as compared to that of PI, which undergoes the same weight loss at about $30^{\circ} \mathrm{C}$ or higher. This loss in the case of PHI is attributed to the presence of a relatively unstable isopropylidene group. The degradation behavior of the PHIHs at higher temperature, however, is markedly different as these showed a gradual weight loss with an

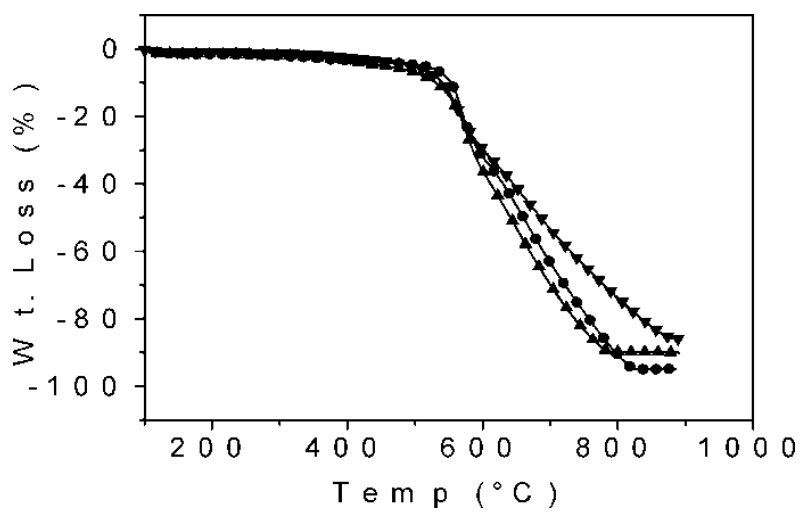

Figure 11. TG curves for PI $(\bullet)$, PIH $5.8(\boldsymbol{\Delta})$ and PHIH $5.8(\boldsymbol{\nabla})$ as a function of temperature; heating rate of $10^{\circ} \mathrm{C} / \mathrm{min}$ under synthetic air, flow rate $=50 \mathrm{cc} / \mathrm{min}$. 
Table 2

Thermal properties of polyimide-silica hybrids

\begin{tabular}{lccccc}
\hline $\begin{array}{l}\text { Hybrid } \\
\text { system }\end{array}$ & $\begin{array}{c}\mathrm{SiO}_{2} \\
(\mathrm{vol} \%)\end{array}$ & $\begin{array}{c}\mathrm{SiO}_{2} \\
(\mathrm{wt} \%)\end{array}$ & $\begin{array}{c}\text { Temp }\left({ }^{\circ} \mathrm{C}\right) \\
\text { for 5\% } \\
\text { wt. loss }\end{array}$ & $\begin{array}{c}\text { Temp }\left({ }^{\circ} \mathrm{C}\right) \\
\text { for } 10 \% \\
\text { wt. loss }\end{array}$ & $\begin{array}{c}\text { Residue at } \\
900{ }^{\circ} \mathrm{C} \\
(\text { wt. } \%)\end{array}$ \\
\hline PI & 0.0 & 0.0 & 540 & 555 & $<2$ \\
PI-5.8 & 5.8 & 10.0 & 535 & 550 & 12 \\
PI-11.8 & 11.8 & 20.0 & 512 & 545 & 22 \\
PI-14.4 & 14.4 & 25.0 & 492 & 500 & 26 \\
HPI & 0.0 & 0.0 & 510 & 543 & $<2$ \\
HPI-5.8 & 5.8 & 10.0 & 535 & 545 & 17.5 \\
HPI-11.8 & 8.8 & 15.0 & 518 & 542 & 25 \\
HPI-14.4 & 14.4 & 25.0 & 510 & 540 & 32 \\
\hline
\end{tabular}

increasing temperature up to $900^{\circ} \mathrm{C}$. This exceptional behavior can be explained due to increased interaction between the polymer chain and the silica. The silica protects the polymer chains trapped in the network from a thermo-oxidative process and thus, hinder the process of degradation. The weight retained above $900^{\circ} \mathrm{C}$ in all the hybrids, was however, found to be proportional to the silica contents used in the matrix, meaning thereby that the sol-gel process was carried out almost completely in the present studies.

\section{Conclusions}

Our studies on PI-Silica hybrids show that few pedant hydroxyl groups on the polymer chain prevent the agglomeration of silica particles and make their distribution more homogenous in the matrix. The improved interfacial interaction between the phases results in better mechanical and thermal properties of the hybrid materials.

\section{References}

1. Mittel, K.L., Ed. (2003) Polyimides and Other High Temperature Polymers; VSP Publishers: Holland, Vol. 2.

2. Ahmad, Z. (2001) The Encyclopedia of Materials: Science and Technology, Section 5; Elsiever Science: LondonChapter 10.

3. Gosh, M.K. and Mittel, K.L., Eds. (1996) Polyimides: Fundamental and Applications; Marcel Dekker: New York.

4. Rabilloud, G. (2000) High Performance Polymers, Vol. 3: Polyimides in Electronics; Editions Technip: Paris.

5. Brinker, C.J. (1986, 1988) Better Ceramics Through Chemistry; Material Research Society: Pittsburgh.

6. Brinker, C.J. and Scherer, G.W. (1990) Sol gel Science; Academic Press: New York.

7. Ahmad, Z. and Mark, J.E. (2001) Chem. Mater., 13: 33203330.

8. Ahmad, Z. and Mark, J.E. (1998) Mater. Sci. Eng., C 6: 183.

9. Spinu, M., Brennan, A.B., Rancourt, K., Wilkes, G.L., and McGrath, J.E. (1990) Mater. Res. Soc. Symp. Proc., 175: 179.

10. Nandi, M., Conklin, J.A., Salviati, L., Jr., and Sen, A. (1991) Chem. Mater., 3: 201. 
11. Morikawa, A., Iyoku, Y., Kakimoto, M., Imai, Y., Masaaki, K., Atsushi, M., Yoshitake, L., and Yoshio, I. (1992) J. Mater. Chem., 2: 679.

12. Morikawa, A., Kakimoto, M., Iyoku, Y., and Imai, Y. (1992) Polym. J., 24: 107.

13. Wang, S., Ahmad, Z., and Mark, J.E. (1994) Macromol Reports, A31: 411.

14. Wang, S., Ahmad, Z., and Mark, J.E. (1994) Chem. Mater., 6: 943.

15. Schrotter, J.C., Smaihi, M., and Guizard, C. (1996) J. Appl. Polym. Sci., 61: 21372149.

16. Chen, Y. and Iroh, J.O. (1999) Chem. Mater., 11: 1218.

17. Chang, C., Wei, K., Chang, Y., and Chen, W. (2003) J. Polym. Res., 10: 16.

18. Kioul, A. and Mascia, L. (1994) J. Non Cryst. Solids, 175: 169.

19. Mascia, L. and Kioul, A. (1995) Polymer, 3: 3649.

20. Menoyo, J.D.C., Mascia, L., and Shaw, S. (1998) J. Mater. Res. Soc. Symp. Proc., 520: 239.

21. Mascia, L., Xenopoulos, C., and Shaw, S. (1998) J. Mater. Sci. and Eng., 6: 99114.

22. Ree, M., Goh, W.H., and Kim, Y. (1995) Polym. Bull., 35: 215.

23. Ruan, S., Lannutti, J., Prybyla, S., and Seghi, R.R. (2001) J. Mater. Res., 16 (7): 19751981.

24. Huang, J.C., Zhu, Z., Zhang, D.J., and Qian, X. (2001) J. Appl. Polym. Sci., 79 (5): 794800.

25. Hisue, G., Chen, J., and Liu, Y. (2000) J. Appl. Polym. Sci., 76: 16091618.

26. Tasi, M. and Whang, W. (2001) Polymer, 42: 41974207.

27. Tasi, M. and Whang, W. (2001) J. Appl. Polym. Sci., 81: 25002516.

28. Cornelius, C.J. and Marand, E. (2002) Polymer, 43 (8): 23852400.

29. Qiu, W., Luo, Y., Chen, Y., Duo, Y., and Tan, H. (2003) Polymer, 44: 58215826.

30. Chin, Y. P. and Jiun, L. H. (1994) J. Polym. Sci. Part A, Polym. Chem., 32: 369382.

31. Person, W.B. and Zerbi, G. (1982) Vibrational Intensities in Infrared and Raman Spectroscopy; Elsevier: Amsterdam.

32. Kerner, E.H. (1956) Proc. Phys. Soc., 69: 808.

33. Counto, U.J. (1964) Mag. Concr. Res., 16: 129.

34. Nielsen, L.E. (1996) J. Appl. Polym. Sci., 10: 97.

35. Seymour, R.B. (1991) Reinforced Plastics: Properties and Applications; ASM International: Ohio.

36. Brinker, C.J. and Scherer, G.W. (1985) J. Non Cryst. Solids, 70: 301. 